\title{
Cultivating Trust and Perceptions of Source Credibility in Online Counternarratives Intended to Reduce Support for Terrorism
}

\author{
Kurt Braddock $^{\mathrm{a} *}$ and John F. Morrison ${ }^{\mathrm{b}}$ \\ aDepartment of Communication Arts and Sciences, The Pennsylvania State University \\ ${ }^{b}$ Terrorism and Extremism Research Centre, University of East London
}

\begin{abstract}
Terrorism researchers have long sought to identify methods for challenging terrorist ideologies. The construction and dissemination of counternarratives has begun to receive substantial attention as a means of doing so. However, the effectiveness of this approach is contingent on message targets' trust in the counternarrative's content and source. This article draws from literatures on trust and online source credibility to offer preliminary guidelines for cultivating trust in counternarratives and their sources. By encouraging trust in this manner, practitioners can reduce the likelihood that their counternarratives will be dismissed by their intended audiences - a perpetual challenge to strategic messaging geared towards countering violent extremism.
\end{abstract}

*Correspondence to Dr. Kurt Braddock, Department of Communication Arts and Sciences, 234 Sparks Building, The Pennsylvania State University, University Park PA 16802. Phone: +1-609-234-6267, Email: kurtbraddock@psu.edu. 
CULTIVATING TRUST IN ONLINE COUNTERNARRATIVES 1

\section{Cultivating Trust and Source Credibility in Online Counternarratives Intended to Reduce Support for Terrorism}

In December of 2013, the U.S. Department of State launched the English-language version of its attempt at online counter-radicalization messaging. ${ }^{1}$ This program, called 'Think Again, Turn Away,' was developed by the State Department's Center for Strategic Counterterrorism Communications (CSCC) and was intended to counter ISIS propaganda by sharing stories and images that challenge ISIS claims and ideology. Counter-messages disseminated by CSCC personnel were largely taken from the media in the form of stories that highlight the mortal and social threats posed by ISIS, as well as videos produced to demonstrate the brutality of the group. Though the CSCC's efforts were a well-intentioned first step in leveraging countermessaging strategies online, the execution of the campaign was largely a failure. Stories posted to Twitter devolved into 'embarrassing' online arguments between the CSCC and ISIS supporters $^{2}$; messages were lampooned by the groups they were meant to challenge; and even CSCC officials grew 'supremely uncomfortable' about sending out counter-messages with the Department of State seal attached to them. ${ }^{3}$ Although the State Department has since revamped and improved its online counter-messaging strategies, its first counternarrative efforts were, at best, unsuccessful.

As illustrated by 'Think Again, Turn Away,' one of the key challenges facing efforts to implement effective counter-messaging campaigns is the difficulty associated with audience distrust in message content and sources. If the source of a message is perceived as untrustworthy, target audiences may dismiss their messages, or worse, engage in behaviours opposite to those advocated. Some researchers have begun to recognize the importance of source credibility in counter-messaging. To illustrate, Braddock and Horgan ${ }^{4}$ recently 
developed a preliminary framework for constructing and disseminating counternarrativesnarratives that discourage engagement in terrorism by challenging the themes that underpin terrorist messages. In their paper, they suggested a set of actionable procedures grounded in communication and psychology theory. In discussing these procedures, Braddock and Horgan emphasised the importance of 'cultivating trust' between counternarrative targets and those perceived as the source of the counternarrative message. ${ }^{5}$ The authors essentially argued that a counternarrative's content is moot if the message recipient did not consider its source to be legitimate and trustworthy. Without this trust, they contended, the counternarrative is likely to be ignored or deemed illegitimate. We seek to provide insight into how these negative outcomes can be avoided by (a) expanding on the role of trust in the use of narratives and counternarratives and (b) providing researchers, practitioners, and policymakers with actionable suggestions for engendering trust in a counternarrative's source, and by extension, its content.

More specifically, this article assesses our understanding of the role of trust in two stages in Horgan's ${ }^{6}$ 'arc' of terrorism: initial terrorist involvement and disengagement. To do so, we discuss how terrorists cultivate trust in their narrative propaganda to improve its effectiveness and how trust in a counternarrative's source and content contributes to one's movement away from terrorism. This is followed by an appraisal of the related issue of source credibility of online communication. The discussion of online source credibility draws from Sundar's MAIN Model, ${ }^{7}$ which identifies content-specific and structural characteristics of online messages that influence the degree to which users attribute credibility to the source of those messages. By integrating these two complementary areas of research, this article will demonstrate the role of trust in counternarrative effectiveness. Insight gained from the analysis of these research areas are then utilised to achieve the article's goal of offering actionable suggestions for increasing 


\section{CULTIVATING TRUST IN ONLINE COUNTERNARRATIVES 3}

the counternarrative target's trust in the message, as well as the credibility of the message's source.

\section{Trust}

Diego Gambetta defined trust as 'a particular level of the subjective probability with which an agent assesses that another agent or group of agents will perform a particular action, both before he can monitor such action (or independently of his capacity ever to be able to monitor it) and in a context in which it affects his own action' ${ }^{8}$. The 'particular action' referred to by Gambetta can relate to a range of possible activities. Included within this is the assessment that an agent will distribute legitimate and reliable information concerning a specific topic. This article seeks to address whether and how it is possible for practitioners to achieve trust in their counternarratives such that their targets accept them (and their perceived sources) as trustworthy.

Before turning to the discussion of terrorism and trust, however, it is important to note that trust can take many forms. Seligman ${ }^{9}$ asserted that an individual can have abstract trust in a system or principle (e.g., trust in democracy), functional trust in practical relationships with others (e.g., trust in a lawyer to defend you), and/or personal trust in relationships that exceed pragmatic outcomes (e.g., trust in a friend). Seligman's notion of personal trust is like Rathbun's ${ }^{10}$ moralistic trust, which is based on an individual's dependability. Rathbun ${ }^{11}$ has discussed the concept of generalized trust, which refers to a person's expectations of societal norms and the likelihood that others will conform to their beliefs and/or behaviors. Each of these forms of trust are relevant to processes related to radicalization and terrorism, so it is important to recognize how trust affects these processes. The next section features a discussion of this relationship.

[INSERT TABLE 1 HERE] 


\section{CULTIVATING TRUST IN ONLINE COUNTERNARRATIVES 4}

\section{Terrorism and Trust}

Before assessing the relationship between trust and counternarratives, it is first necessary to understand the role that trust plays in the psychology of terrorist engagement. Trust plays a critical role in the decision-making processes across a terrorist's 'career' and is a central element of each stage of Horgan's ${ }^{12}$ Involvement, Engagement, and Disengagement (IED) arc model. ${ }^{13}$ This section outlines how trust affects the stages of this arc, with particular emphases on the processes of initial involvement (Stage 1) and disengagement (Stage 3).

\section{Initial Involvement and Disengagement}

\section{Initial Involvement}

Much of the existing literature on why and how a person joins a terrorist group focuses on the concept of violent radicalisation a 'social and psychological process of incrementally experienced commitment to an extremist political or religious ideology' such that an individual is at increased risk for engaging in violence ${ }^{14}$. For many researchers, this is a precursor to involvement with a terrorist group, and is the most critical phase of one's engagement in terrorist activity ${ }^{15}$. However, exalting the process of violent radicalisation at the expense of other factors limits our understanding of the conditions necessary for an individual's engagement in terrorism. ${ }^{16}$ It is necessary to expand the scope of extant analyses to understand the process by which an individual becomes initially involved with a terrorist group. A significant part of this process may be influenced by an individual's trust and/or distrust of salient entities. A significant amount of research on terrorism has drawn conclusions to this effect.

For example, in her analysis of terrorism and trust in Northern Ireland, Fierke ${ }^{17}$ highlighted how the 1972 Bloody Sunday killings cultivated widespread distrust of the British Government 


\section{CULTIVATING TRUST IN ONLINE COUNTERNARRATIVES 5}

and its security forces among the Irish nationalist and republican populations. The general distrust of the British Government strengthened trust in the Provisional IRA (PIRA) to protect the republican communities. In this way, Bloody Sunday served as the most effective recruitment tool for the PIRA in some of the most contentious years of the Troubles.

In the wake of Bloody Sunday, the process of radicalisation (as conceptualised by many terrorism researchers) did not guide the rationale behind an individual's membership in the PIRA. Movement towards (and subsequent membership in) the PIRA did not require ideological commitment or transformation. Many joined the group not to fight for a united Ireland, but to protect against what they perceived to be threats to their community. These individuals placed functional trust in the PIRA to successfully provide this defence.

Although past research on trust and terrorism has not emphasised the process of violent radicalisation, one should not dismiss trust's role with respect to an individual's initial engagement with a terrorist group. For instance, Hegghammer ${ }^{18}$ contended that when a terrorist is recruited, there is a 'trust game' between the recruiter and the potential recruit. Related to this, Morrison ${ }^{19}$ contended that a potential recruit must have functional trust in the group if recruitment is to be successful. This functional trust need not be related to the organisation's ultimate objective, but to that which they require of the group more immediately (e.g., defence against another group, the thrill of engaging in dangerous activities). It is also important for the existing membership of the group to trust their potential new comrade. Recruiters must trust that new recruits are ideologically committed and will not risk the security of the existing network. 
In the final phase of Horgan's ${ }^{20}$ arc model, individuals undergo a process of psychological and/or physical disengagement. Psychological disengagement (referred to by some as deradicalisation) is a process of belief and/or attitude change whereby an individual no longer adheres to his former group's ideology. Physical disengagement relates to the stoppage of terrorist activity. ${ }^{21}$ It is important to note that physical disengagement can occur in the absence of psychological disengagement, and psychological disengagement can occur without the individual physically disengaging.

As with the initial involvement phase, trust plays a key role in the process of psychological disengagement. At the very heart of an individual's psychological disengagement is a deterioration of abstract trust in the terrorist group's ideology and justifications for engaging in violence. This deterioration can occur for a variety of internal and/or external factors that lead to an individual's questioning their group's ideology and legitimacy.

Related to this, a recent meta-analysis assessed why individuals psychologically disengage from terrorist groups. ${ }^{22}$ Of the thirteen reasons identified in the analysis, eight can be linked with the dichotomous theme of trust/distrust:

- Mistreatment

- Ideological Differences

- Differences in Tactical Preferences

- Differences in Strategic Preferences

- Disillusionment with Group Hypocrisy

- Unmet Expectations

- Cognitive Dissonance

- Loss of Social Support 
A cursory assessment of these factors shows that they are intrinsically related to deterioration in functional, abstract, moralistic, or personal trust. Consider, for example that mistreatment can weaken an individual's personal trust of a group and its other members. Differences in strategic and/or tactical preferences, unmet expectations, and a loss of support can damage an individual's functional trust in his group. Ideological differences, group hypocrisy, and cognitive dissonance can deteriorate an individual's abstract trust. Finally, a person's moralistic trust can wane if their ideological purity or strategic adherence is called into question. $^{23}$

Horgan $^{24}$ explained that among other factors, psychological disengagement from a terrorist group can be catalysed by feelings of disillusionment developed from an imbalance between an individual's lofty expectations about the group's operations and their experienced reality of involvement. In short, the weakening of the terrorist group's credibility can prompt feelings of disappointment and disillusionment with the group. Consider, for example, the case of Omar Nasiri, a former member of al-Qaeda. In an account of his life as an al-Qaeda operative, Nasiri described an interaction with London-based operative, Abu Hamza:

Hamza asked me which of the camps in Afghanistan I had been in, and I told him. Then I leant forward slightly. 'I met someone you know,' I said in a conspiratorial voice. Hamza raised his brow just slightly. 'I trained with Assad Allah,' I told him. 'He told me about the nitroglycerine, and how you lost your hands.' Hamza looked away. 'Brother,' he whispered, not meeting my gaze, 'please don't share that story with anyone.' As I was to learn later, 


\section{CULTIVATING TRUST IN ONLINE COUNTERNARRATIVES 8}

Hamza claimed he had lost his hands defusing a landmine on the front lines in Afghanistan. I knew the real story. ${ }^{25}$

In presenting this story, Horgan ${ }^{26}$ demonstrates the extent to which terrorist entities like alQaeda preserve myths to maintain their credibility among potential recruits and current members. A loss of that credibility can result in a loss of trust in the group's leadership and ideology, which in turn, can motivate individuals to leave the group. This was the case with Omar Nasiri.

Prior to joining a terrorist group, some individuals have idealised notions of its ideological purity and tactical capabilities. However, the reality of organisational membership in a terrorist group frequently contradicts these idealised notions. An ideological 'purist' joining the group may become disillusioned after interacting with their new, less-devout comrades. This can highlight ideological discrepancies between a group's external narrative and internal reality. For instance, research on al-Qaeda members has shown that individuals have left the group due to its interpretation of Islam. ${ }^{27}$ This manifested as a lack of religiosity among the group's leadership, criminality among its rank-and-file members, and pervasive greed throughout the organisation. These attributes contradicted the purified public image that the group has historically sought to portray. These ideological differences, coupled with the observable hypocrisy associated with acting in contradiction to the organisation's stated ideals, can lead individuals to lose abstract trust in the organisational ideology and the moralistic trust they have in their comrades.

These observations relating to the initial involvement and disengagement phases of Horgan's arc model illustrate the importance of trust throughout a terrorist's career. ${ }^{28}$ Given its centrality, 
particularly with respect to disengagement, it is imperative that factors that influence trust are considered in any strategy intended to reduce support for terrorism, including the development and dissemination of counternarratives.

Unfortunately, terrorism researchers have yet to sufficiently address how trust influences the efficacy of counternarratives. Braddock and Horgan's work suggested the importance of trust in the dissemination of counternarratives, but provided little guidance for cultivating that trust. $^{29}$ They argued that a counternarrative's credibility can be improved by distributing it via trusted channels (e.g., trusted community leaders, anonymous online comrades), but did not provide specific guidelines on how to utilise these channels or develop counternarrative messages that exploit their affordances.

To effectively facilitate distrust in a terrorist group or ideology via counternarratives, it is important for the individual to trust the source of any message designed to promote disengagement. Failure to deliver counternarrative messages from a trusted source risks having the intended target dismiss or argue against the counternarrative. Therefore, it is essential that that the vehicle through which counternarratives are delivered is credible with its intended audience.

To this end, the remainder of this paper will focus on source credibility and its implications for the efficacy of counternarratives. Expanding on the work of Braddock and Horgan and drawing from a seminal literature on source credibility from the field of communications, the following sections assess how credibility is conveyed to audiences in what has become a modern-day 'ground zero' for terrorist recruitment and radicalisation — the Internet. 


\section{Credibility and the Internet}

The proliferation of the Internet as the world's principal communication technology has afforded terrorist groups the ability to reach individuals to whom they might otherwise lack immediate access. Terrorism researchers have long-shown that terrorist groups utilise the Internet for communicative, coordinative, and instrumental purposes. ${ }^{30}$ The utility of both traditional Internet technologies (e.g., websites, discussion fora) and Web 2.0 social media platforms (e.g., Twitter, Facebook) for accessing potential recruits around the world has become strikingly evident with the emergence and recruiting successes of tech-savvy groups like ISIS. ${ }^{31}$ Given the potential for Internet-based technologies to influence and motivate recipients of terrorist groups' messages, it is imperative that those who seek to counter those messages consider how Internet-based messages can challenge terrorist narrative propaganda.

To this end, Sundar identified four specific types of affordances that may exert significant psychological effects on those that engage with messages on the Internet. ${ }^{32}$ Although Sundar's explication of these affordances did not speak specifically to terrorism, they refer to the structural aspects of Internet-based communication technologies, and as such, can inform research on terrorist messaging and counter-messaging in online contexts. These affordancesmodality, agency, interactivity, and navigability — are manifest in most digital media and cue heuristics related to judgments about a message source's credibility. ${ }^{33}$ As such, these four affordances can affect how target audiences will perceive the credibility of the source of Internet-based counternarratives.

Internet-based technologies stand as the most salient examples of communication technologies for which structural aspects can be varied contingent upon the preferences and goals of message 
designers. Sundar claimed that the nature of the psychological and behavioural outcomes associated with these affordances is largely dependent on how they are manifest within the medium itself. ${ }^{34}$ So, a consideration of how the affordances affect terrorist messaging can provide some insight into the nature of the psychological and behavioural effects that can be expected among those that encounter terrorist messages. More importantly, a consideration of the affordances in the production and dissemination of counternarratives can promote source credibility among their distributors, thereby increasing their effectiveness. The following sections summarize the four affordance types that comprise Sundar's MAIN model, as well as several associated heuristics that can influence a message's perceived credibility. Following these summaries, we offer a more focused discussion on how these affordances and heuristics can influence audiences of counter-terrorist messaging as a function of the trust they cultivate.

\section{The MAIN Model}

Sundar's MAIN model is based on a long tradition of research showing that the four affordance types - modality, agency, interactivity, and navigability — are present to some extent in all digital media and prompt 'significant psychological effects' in those that engage with them. ${ }^{35}$ The manifestations of each affordance can lead to positive or negative assessments concerning the credibility of the source of a message and the Internet-based conduit through which it is expressed.

The MAIN Model outlines how different affordances manifest in terms of their application, design structure, or quantity, each of which can affect an individual's judgments of a message's source. ${ }^{36}$ More specifically, the model shows how modality, agency, interactivity, and navigability can cue certain cognitive shortcuts (hereafter, 'heuristics') about the credibility of a message and its source. Figure 1 offers a visual representation of the MAIN Model. 
[INSERT FIGURE 1 HERE]

To determine how the MAIN Model can be applied to inform the development and dissemination of counternarratives, we now turn to the four key affordance types and describe how their manifestations can cue certain heuristics. Whereas modality and agency cues relate to the content of counternarratives, the interactivity and navigability cues relate to how counternarratives are embedded in online interfaces. Both sets of cues are important for the effective distribution of counternarratives, as they both influence audience perceptions of credibility in relation to those counternarratives, as well as their sources.

For the sake of parsimony, the following sections will offer general descriptions of each affordance type before summarising heuristics salient to the development and online distribution of counternarratives.

\section{Modality Cues and Associated Heuristics}

Modality refers to the method by which a message is delivered. The Internet provides terrorist groups with several means with which to disseminate their messages, particularly since the emergence and proliferation of Web 2.0 platforms like Twitter, Facebook, and other social media technologies have facilitated direct contact between terrorist groups and their audiences. As evidenced by the multimedia campaigns launched by groups like ISIS, terrorists and their supporters can utilise basic text, photographs, pre-recorded video, live-casting, podcasting, and a multitude of other communicative media to reach audiences. Fortunately, it is possible to use those same media to disseminate counternarratives intended to challenge terrorist propaganda. 
Still, the decision to distribute counternarratives online raises questions concerning the psychological effects on those that are exposed to them. One of the most pertinent questions to be considered in the development and distribution of online counternarratives relates to potential heuristics that may be triggered by presenting information via certain modalities and whether these heuristics positively or negatively affect perceptions of online counternarrative quality or credibility. Table 1 outlines various heuristics associated with modality-based cues, as well as the implications of these heuristics as theorized by the MAIN model.

\section{[INSERT TABLE 2 HERE]}

\section{Agency Cues and Associated Heuristics}

Identifying sources of online content can be difficult, ${ }^{37}$ and judgments of content reliability are largely dependent on perceptions of its ostensible source. Developers of counternarratives can take advantage of this uncertainty by attributing information to 'particular entities in the chain of communication' to increase user perceptions of message credibility. ${ }^{38}$ It may also be useful for developers of counternarratives to attack the credibility of terrorist narratives suggesting their sources are untrustworthy. Before delving into specific methods for leveraging agency cues to improve credibility of online counternarrative content and sources intended to challenge terrorist narratives, we first outline agency cues and heuristics more generally. Table 2 summarises various heuristics associated with message sourcing and how they might affect perceptions of credibility and trust in online content.

[INSERT TABLE 3 HERE] 
As with modality-based cues and heuristics, different agency cues will be more central to judging the quality and credibility of online content and sources in different contexts. For example, the machine heuristic will prompt more favourable judgments about content that highlights 'factual' information. The social presence heuristic, by comparison, will prompt more favourable judgments about content with a socioemotional focus. The unique nature of terrorist ideologies as emotion-laden concepts requires a close empirical examination of how sourcing affects audience perceptions of the content being presented. These issues will be addressed in greater detail below where we offer specific guidelines for analysts and practitioners for leveraging agency-related cues and heuristics in the development of online counternarrative content.

\section{Interactivity Cues and Associated Heuristics}

Perhaps the most obvious outcome associated with the rapid development of digital media is the degree to which interactivity has become an integral part of online communication. Although there exist several definitions of interactivity, many from before the proliferation of the Internet, ${ }^{39}$ Sundar and colleagues summarised these definitions and brought them to bear on the modern nature of digital media. ${ }^{40}$ They described interactivity as the potential for users to be both sources and recipients of content. As outlined above, the emergence and growth of Web 2.0 social media platforms has fundamentally changed how we interact with content on the Internet. But regardless of changes to the Web and how we engage with it, the basic premise of interactivity is constant; it refers to the process by which an individual provides inputs into a communication system and receives some form of feedback in return. Sundar's MAIN Model identifies multiple heuristics associated with interactivity that may influence the credibility of 
terrorist narratives and counternarratives. Table 3 lists a few of these heuristics, as well as their implications for the credibility of the content that cues them.

\section{[INSERT TABLE 4 HERE]}

Because interactivity has been conceptualized in several ways, there exist a multitude of potential cues and heuristics that relate to it. The sample discussed here represents only a few of these heuristics, chosen on the basis of their importance for counternarrative dissemination. As digital media evolve, however, the interactive features of computer-mediated communication will continue to change. As a result, new cues and heuristics regarding perceptions of quality and credibility are likely to emerge. As the technology allows, some interactivity-related cues and heuristics will interact with one another. As such, it will be critical for developers and distributors of counternarratives to remain abreast of the features inherent to these new technologies and what psychological effects they could trigger.

\section{Navigability Cues and Associated Heuristics}

Because digital media are distinct from traditional print, audio, or visual media in their ability to transmit information, the need to follow a linear style does not apply to online content. Website layouts, social media platforms, and other online contexts allow users to 'navigate' to different points on the Web at their leisure, making for an information consumption process that follows a non-linear trajectory. The functions through which navigability manifests can serve as cues that influence the degree to which the quality and credibility of online content is positively or negatively assessed. Although the computer-mediated communication literature identifies several heuristics associated with navigability cues, Table 4 summarises the two most 
salient for the dissemination of counternarratives: the elaboration heuristic and the scaffolding heuristic.

\section{[INSERT TABLE 5 HERE]}

\section{Summary of Cues and Heuristics}

It is critical to recognise that the cues and heuristics summarised in Tables 1-4 do not operate in isolation, nor do they all apply in every online context. Some heuristics may be triggered in response to one online message, but not for another. Therefore, this list of heuristics and their predicted effects should not be considered the final word on psychological responses to online content. However, they do provide a useful starting point for thinking about content, sourcing, and online structural characteristics that might improve the degree to which targets of counternarratives can come to trust their sources. Consistent with the work of Braddock and Horgan, ${ }^{41}$ these cues and heuristics can be used to derive a set of preliminary guidelines for cultivating trust in counternarrative messages and sources. The following section draws on the MAIN Model and its components as summarised in Tables 1-4 to offer such guidelines.

\section{Preliminary Guidelines for Cultivating Trust in Counternarrative Messages and Sources}

This section offers a set of recommendations - respectively related to modality cues, agency cues, interactivity cues, and navigability cues - to assist in the cultivation of trust in developing and distributing online counternarratives intended to reduce support for terrorism. These guidelines are sufficiently broad as to facilitate their application across a range of contexts. However, it is essential that individual counternarratives be tailored to the specific context in 
which they are applied. ${ }^{42}$ This means that although authors and distributors of counternarratives can effectively apply these guidelines, they must also consider the timing of their dissemination, the type of terrorist group (and ideology) being challenged, the internal dynamics of the terrorist group being targeted, and other related issues.

\section{Modality Cues}

\section{Realism Heuristic}

Because terrorist narratives often attempt to persuade individuals to support the group through idealised depictions of engagement, it is important for counternarratives to provide realistic challenges against those depictions. Therefore, counternarratives should be presented via

media (or combinations of media) that can vividly portray the negative real-life experience of terrorist engagement, many of which have been documented in interviews with former terrorists. ${ }^{43}$ Many former terrorists have expressed significant disillusionment related to their involvement in terrorism. For instance, Horgan has interviewed many former terrorists who have described vast differences between their expectations and the realities of engagement. ${ }^{44}$ These interviewees have described situations in which they have been disappointed by their superiors, grew lonely for their families, or simply became bored from the tedium of day-today involvement with the group. Authors of counternarratives can use these stories of disillusionment to challenge terrorist narratives. Moreover, by supplementing traditional text with audio, visual, or audio-visual cues, authors of counternarratives can (a) promote transportation into counternarratives, which is often a precursor to successful persuasion, ${ }^{45}$ and (b) bolster the credibility of the messages contained therein by increasing the realism of the counternarrative. 
Modality Recommendation 1: Use multiple modalities (i.e., text, audio, and video) simultaneously to present online counternarratives that depict disappointing realities of involvement in terrorism.

\section{Old Media Heuristic}

The old media heuristic proposes that content presented as if it were in a newspaper is likely to be deemed credible. However, when deciding on the format with which to present a counternarrative, its author must first consider which formats and sources of information would be most credible to the target audience. Because counternarratives should be tailored to contain information that contradicts or discredits terrorist narratives, ${ }^{46}$ there is no guarantee that a counternarrative should contain information that would lend itself to being reported in a newspaper. As such, counternarratives presented as 'old media' will not necessarily prompt perceptions of credibility towards the counternarrative's content or source.

Moreover, in an era in which many individuals doubt the truthfulness of the news produced by media outlets, ${ }^{47}$ it is altogether possible that counternarrative targets will consider information presented via traditional media as untrustworthy. For example, there is evidence to suggest that individuals of different age groups attribute credibility to different source types; in certain cases, newspaper content is not judged as most credible. ${ }^{48}$ Taken together, these factors suggest that authors and distributors of counternarratives should avoid wholesale adherence to a strategy of presenting messages as if they were in old media. Audience analysis techniques should be undertaken to determine whether and the degree to which audience members would attribute credibility to these classic gatekeepers of information. 
Modality Recommendation 2: Present online counternarrative content as if it were from an official news source (e.g., a news reporting agency) only if an analysis of the audience indicates trust in old media sources.

\section{Being-There Heuristic}

Because immersion facilitates persuasion among audience members, ${ }^{49}$ it is imperative for counternarratives to effectively discredit or replace terrorist groups' immersive depictions of reality. To effectively counter terrorist groups' immersive narratives, ${ }^{50}$ it is necessary to provide a similarly immersive counternarrative that highlights the group's ideological, strategic, and tactical hypocrisies, ${ }^{51}$ as well as the mistreatment of group members and rival factions. This can be achieved with counternarratives that employ vivid language, characters that are similar to audience members, and visual material that can intensify audience members' potential transportation into the counternarrative. Triggering the being-there heuristic in this manner can garner moralistic, functional, and societal distrust in the group, their depiction of 'reality', and the organisational morality of the group. By activating the being-there heuristic, authors of counternarratives can challenge what may initially appear to be a credible depiction of terrorist reality through vivid portrayals of the negative realities associated with engagement in terrorism (much like the realism heuristic).

Modality Recommendation 3: Use vivid language, characters similar to the target audience, and supplementary visual material to intensify audience immersion into counternarratives.

\section{Distraction Heuristic}


A comprehensive counter-messaging operation is likely to be comprised of multiple counternarratives spread across various modalities. As such, there is considerable risk for counternarrative authors to present a splintered message if the themes in the various counternarratives are not consistent. Therefore, it is important that counternarratives targeted at a particular audience are consistent across modalities in terms of the themes they promote so as not to distract the target audience from the counternarratives' central purpose(s). In addition, the messages presented via multiple modalities should be sufficiently easy to process so as not to require significant cognitive effort to interpret.

Modality Recommendation 4: Facilitate counternarrative processing by ensuring that the central counternarrative themes presented across multiple modalities are clear and consistent.

\section{Intrusiveness Heuristic}

Although new and emergent digital technologies afford counternarrative authors and analysts a wide array of modalities for disseminating counternarratives, some of these may not be optimal for disseminating counternarratives. To this point, the use of an invasive modality (e.g., pop-ups, unsolicited videos) for counternarrative dissemination is strongly discouraged, as perceptions of intrusiveness are likely to yield negative judgements of the message's quality and credibility. Although intrusive forms of communication may result in a greater number of people seeing a counternarrative, its presentation is likely to annoy a significant number of counternarrative targets. This annoyance is likely to cause individuals to dismiss the message, or worse, induce a boomerang persuasive effect. ${ }^{52}$ 
Modality Recommendation 5: Avoid distributing counternarratives with intrusive communicative tools that present unexpected or unsolicited content.

Agency Cues

Machine Heuristic

If information is presented such that it is evident that a non-human entity selected and distributed the information, it may be perceived as objectively selected, and therefore, more credible. This is particularly true if the information in the message is factual (rather than socioemotional) in kind. Therefore, if a counternarrative contains informational content relating to the terrorist group, politics, or violent activities, it may be useful to present the counternarrative as if it were objectively selected for presentation, possibly by computer algorithm. The machine heuristic dictates that doing so can heighten trust in the counternarrative's content and source, while also fostering distrust of the terrorist group's subjective selection of the information they present. If, however, a counternarrative contains content intended to challenge ideological or emotional arguments, the credibility of that counternarrative may not be aided by presenting it in such a manner.

Agency Recommendation 1a: If counternarrative content is primarily factual in kind, present the counternarrative as if it were objectively selected by a machine algorithm (e.g., Facebook 'newsfeed').

Agency Recommendation 1b: If counternarrative content is primarily emotional or ideological in kind, do not present the counternarrative as if it were objectively selected by machine algorithm. 


\section{Bandwagon Heuristic}

Terrorism researchers have found that individuals often choose to engage in violence as a function of the support received from family members or close friends. ${ }^{53}$ This is unsurprising; individuals often turn to their peers to make judgments about how to process and act on information. Luckily, this tendency can also be leveraged in the development and dissemination of counternarratives intended to dissuade individuals from engaging in terrorism. Specifically, counternarratives that are endorsed by (or presented as if they are endorsed by) individuals that target audiences would perceive as similar to themselves are likely to be judged as credible by those target audiences. As such, having the perceived peers of target audiences distribute (or endorse) counternarratives may render them more credible, and therefore cultivate greater trust in the counternarrative content.

Agency Recommendation 2a: Recruit peers of target audiences to assist in the presentation or endorsement of counternarratives.

Agency Recommendation 2b: Present counternarratives in contexts that suggest peer endorsement.

\section{Authority Heuristic}

Messages (including narratives and counternarratives) are likely to be deemed credible if they are perceived as coming from a trusted expert or authority figure on the topic. Therefore, consistent with Braddock and Horgan, ${ }^{54}$ it is likely that the most effective counternarratives 
will come from ideological leaders, former members, or other authority figures within a specific movement. Alternatively, counternarratives can also be framed as being about these individuals and their negative experiences with the terrorist group. This allows the target audience to receive an alternative interpretation of a terrorist group, its action, and its ideology from an individual or organisation representing the same community and with expertise derived from their experiences within the group. To this end, former members of terrorist groups, ${ }^{55}$ members of a community that a terrorist group claims to represent, ${ }^{56}$ and ideological leaders with an interest in challenging terrorist messaging ${ }^{57}$ can wield significant influence over those at risk for violent radicalisation. It follows that counternarratives presented (or framed as presented) by one of these authorities may be effective in challenging terrorist narratives. This was one of the key areas where 'Think Again, Turn Away,' struggled. By being officially connected to Department of State the messages were not perceived as coming from a trusted source by the target audience.

Agency Recommendation 3: Recruit authority figures (e.g., former members of terrorist groups, community members, ideological leaders) to distribute counternarratives.

\section{Social Presence Heuristic}

Online socioemotional content that explicitly promotes feelings of camaraderie and connection with other web users is qualitatively different than content that appears to be informational in kind. So, in contrast to the machine heuristic, which suggests that objective selection of counternarratives would be useful if the counternarrative content is factual in kind, the social presence heuristic dictates that counternarratives primarily comprised of socioemotional content be presented as if they were chosen by a person. This allows the recipient of the 
counternarrative to develop a feeling of association with the counternarrative's author, perhaps to the point of feeling a sense of sympathy or camaraderie. If socioemotional content relating to negative experiences or interpretations of the terrorist group's ideology is presented by an individual (rather than a machine), the content and source are more likely to be considered credible and trustworthy. In contrast (and as argued in Agency Recommendation 1b), socioemotional content that is presented as if it were selected by a machine is likely to be dismissed.

Agency Recommendation 4: Emphasize the humanity of the source of counternarratives comprised of socioemotional or ideological content (particularly if the source is similar to the intended audience).

Interactivity Cues

\section{Activity Heuristic}

Although all the heuristics presented in this paper require a consideration of context when disseminating counternarratives, it is particularly true when triggering the activity heuristic. Mood management theory suggests that individuals seek out media that will help them develop or maintain a positive mood. ${ }^{58}$ For example, when a user is bored, a higher level of activity may trigger positive judgments about the interface with which he/she is engaging. However, because counternarratives (a) are likely to depict serious content, and (b) require a measure of focus to trigger the identification, transportation, and parasocial interaction processes that make them persuasive, ${ }^{59}$ it follows that too much activity on the part of the user would detract not only from the counternarrative's credibility, but also the likelihood of it even being seen. 
Therefore, it may be useful for counternarratives to be disseminated via interfaces that do not require substantial activity on the part of the user.

Interactivity Recommendation 1: Limit the amount of user activity needed to consume counternarrative content (e.g., 'slideshows' that require constant clicking to navigate).

\section{Interaction Heuristic}

When a counternarrative is presented in an interface that has been tailored by the recipient, it is likely that the counternarrative is likely to be deemed credible. After all, if the user tailored the online interface to his/her preferences, the information presented in that interface are likely to be perceived as being selected by the user him/herself. In this way, counternarratives presented in online contexts that facilitate interaction may be deemed more credible and trustworthy. It is important to note that this proposal is not contradictory to predictions associated with the activity heuristic. Whereas the activity heuristic relates to the counternarrative itself, the interaction heuristic relates to the interface on which it is presented. This has significant implications for counternarrative strategies employed on Web 2.0 platforms like Facebook or Twitter.

Interactivity Recommendation 2: Present counternarratives in a manner consistent with preferences solicited by the user via the online interface.

\section{Choice Heuristic}


A well-organized online interface is likely to be perceived as more credible than a disorganized one. As a result, counternarratives should be presented in a well-organized online interface that provides audiences with choices about which content to engage with (via a drop-down menu, for example). Counternarratives presented via online interfaces that are disorganized are likely to have two negative implications. First, the disorganization will make it difficult for the user to find and engage with counternarrative content. Second, a disorganized interface that provides the user with choices about what content to engage with is likely to be perceived as unreliable, given that the information will be scattered and messily structured.

Interactivity Recommendation 3a: When information in an online interface is well-organized, provide the target audience with specific choices about what counternarrative content to engage with.

Interactivity Recommendation 3b: When information in an online interface is not wellorganized, do not provide the target audience with specific choices about what counternarrative content to engage with.

\section{Control Heuristic}

New digital technologies allow information to be presented in a variety of ways. In some cases, the manner in which information is presented does not afford users the time or capacity to engage with the content, thereby reducing its impact (e.g., stories that automatically scroll across the interface). Counternarratives should be presented in such a way that users are afforded the control over the temporal and structural elements of the interface in which they appear. Because the efficacy of counternarratives is at least partially contingent on the 
systematic processing of the information found within, ${ }^{60}$ it follows that an interface that allows for user control over how information is presented would improve user perceptions of the counternarrative's (and its source's) credibility.

Interactivity Recommendation 4: When a counternarrative contains sufficient information that the online interface must 'scroll' through the content, provide the user with the capacity to control the speed and manner with which the counternarrative is revealed.

\section{Contingency Heuristic}

Thus far, our discussion of interactivity has focused exclusively on user interactions with media. However, interactivity does not relate only to interaction with a communication medium; it is also important for counternarrative authors to consider how the online platforms in which counternarratives are presented facilitate interaction with other individuals. As such, an effective counternarrative strategy should make use of interfaces that facilitate person-toperson interaction. This is particularly applicable for counternarratives hosted on Web 2.0 platforms. This interactivity will promote perceptions of authority and reliability among users (regarding their perceived communicative partners). This, in turn, can improve the credibility of counternarrative content, thereby making it more persuasive.

Interactivity Recommendation 5: Distribute counternarratives in interfaces within which users can communicate with one another, particularly if some users are already (a) respected authorities within the online community, and/or (b) sympathetic to the counternarratives' goals. 
Navigability Cues

\section{Elaboration Heuristic}

When triggered, the 'elaboration heuristic' gives users the impression of comprehensivenessthat the information presented is complete and thorough. ${ }^{61}$ Information perceived as thorough is typically considered credible. Moreover, because counternarratives are most optimally presented as part of larger, wide-ranging counter-messaging campaigns, comprehensive information related to counternarrative content may help audiences contextualise and interpret that content. When presented in isolation, counternarratives may be interpreted devoid of context, leaving it susceptible to misinterpretation. In this vein, counternarratives are likely to be most effective when they are presented via an online interface or platform that facilitates access to complementary information related to the counternarrative content. The elaboration heuristic dictates that this will improve perceptions of the content's quality, and therefore, improve judgments of the counternarrative author's credibility among message targets.

Navigability Recommendation 1: When counternarratives are part of a larger countermessaging strategy, facilitate user navigation to information that complements the themes that comprise the counternarrative.

\section{Scaffolding Heuristic}

It is sometimes advisable for web designers to direct users to certain parts of websites over others. For instance, some designers may present clickable links in an organized hierarchy, with larger links being representative of more important information. ${ }^{62}$ The gratitude felt by 
users for this guidance is likely to yield perceptions of content quality and source credibility. Given this, it is likely that presenting counternarratives hierarchically—whether on a traditional website or Web 2.0 interfaces - will improve audience perceptions of the counternarrative's (and its source's) credibility. ${ }^{63}$

Navigability Recommendation 2: Present online counternarratives hierarchically such that users are clearly directed to content that is most salient.

\section{Moving Forward}

Empirical Testing of Guidelines for Disseminating Online Counternarratives

As emphasised above, the guidelines proposed here are not meant to be the final word on the presentation of online counternarratives. They should instead be interpreted as viable starting points for empirical work that evaluates (a) how and when these cues and heuristics operate, (b) how the heuristics interact, and (c) which heuristics are most potent in response to terrorist narratives and counternarratives. To this end, there are several avenues of future research related to these cues and heuristics that would be useful for guiding the dissemination of online counternarratives.

First, terrorism researchers should strive to test these heuristics in relation to counternarratives via experimental methods. Research on computer-mediated communication practices have long-used experimental manipulations to test the psychological effects of Web-based structural elements and the content contained therein. Terrorism researchers should follow suit. For example, the contingency heuristic dictates that counternarratives may be judged as credible to 
the degree that they are presented in an online interface that allows for person-to-person interaction. Future researchers could test this prediction by manipulating the interactive features on Web-based platforms.

Another example would be to experimentally test the interaction between counternarrative content and heuristic triggers. For instance, informational content or socioemotional content should be judged as more credible if a message's author is able to respectively trigger the machine heuristic or social presence heuristic. Terrorism researchers should test this possibility with terrorist narratives and counternarratives, two kinds of value-laden communication that may not yield the same results as more traditional kinds of Web content. Morrison and Braddock $^{64}$ have begun work to this effect, but the sheer number of cues and heuristics that require investigation leaves room for a substantial amount of future work in this domain.

Second, future researchers may benefit from exploring how these heuristics are triggered via different kinds of digital interfaces. The proliferation of Web 2.0 social media platforms has fundamentally changed the way we consume information. Many of Sundar's ${ }^{65}$ heuristics are geared towards explaining psychological reactions to more traditional, static Web content, but for those that seek to effectively challenge the narratives of today's media-savvy terrorist groups, it is necessary to utilize equally dynamic methods of counternarrative delivery. To this end, it would be useful to experimentally test the potency of the MAIN Model's cues and heuristics in response to counternarratives delivered via not only traditional social media platforms like Facebook and Twitter, but also more unorthodox platforms like Instagram and Snapchat (both of which allow for user presentation of 'stories' through a series of images or video), as well as direct messaging programs (e.g., Telegram ${ }^{66}$ ) that terrorist groups have come to exploit. 
Finally, future scholarship would benefit from exploring how the cues and heuristics outlined in this paper interact with other theories of persuasion. For instance, some of the heuristics (e.g., the being-there heuristic, the realism heuristic) relate to audience immersion in online content. Related to this, there is a substantial amount of extant work to show psychological transportation, identification with narrative characters, and parasocial interaction to be mediators of the relationship between exposure to a message and persuasion. Given this, it may be useful to explore the degree to which some of the heuristics affect these precursors to persuasion.

Putting the Guidelines into Practice

In addition to the aforementioned avenues of future scholarship, this paper also has implications for the future development and distribution of counternarratives in practice. First, although the cues and heuristics discussed here were originally described in relation to traditional computer-mediated platforms, they also apply to the digital communication technologies that have since emerged. As such, the psychological effects associated with these heuristics can be exploited through the dissemination of counternarratives via these new digital channels (e.g., Telegram, WhatsApp, mobile-exclusive social media). Analysts have certainly attempted to challenge terrorist propaganda via these channels, but it is unlikely that counternarrative content has been tailored to match the psychological effects of the heuristics prompted by the channels' affordances. To cultivate trust in counternarrative content (and sources), analysts and policymakers should consider how communicative affordances are manifest in new digital technologies and whether their counternarratives - if presented via 
these technologies - effectively cue positive judgments from intended audiences per the guidelines above.

Second, as argued by Braddock and Horgan, ${ }^{67}$ the effective distribution of counter-narratives requires close coordination between developers of counternarratives and trusted leaders in the communities in which they are to be disseminated. The authors contended that former members of terrorist groups or members of the community the group purports to defend make promising conduits through which counternarratives can be disseminated. Many of the heuristics described above reiterate the importance of these kinds of individuals. By presenting online counternarratives via trusted sources, practitioners can take full advantages of these heuristics (e.g., the authority heuristic) to foster trust in counternarrative content.

Finally, many of the cues and heuristics described in this paper are based on message delivery methods that transcend traditional text, graphics, or multimedia content. For instance, our interactivity-based recommendations are largely based on dynamic user engagement with counternarrative content (e.g., inputting preferences for message presentation) and the seamless presentation of that content in response to user actions. Cultivating trust in online counternarratives presented using these innovative communication tools requires expertise in platform development, coding, and web design. Therefore, practitioners charged with developing and distributing online counternarratives should coordinate with web designers, coders, and programmers that can translate counternarrative content into vibrant, engaging stories amenable to presentation via new digital platforms. For instance, in cooperation with experts on virtual reality platforms and programming, Braddock is currently testing the efficacy of counternarratives presented in simulated reality environments. ${ }^{68}$ As methods for delivering 
online counternarratives grow more technologically intricate, partnerships between counterterror researchers, practitioners, and programming experts will become critical.

\section{Closing Remarks}

When effective, counternarratives are transformative at multiple levels. They can change audience perceptions of a terrorist group, make the group's members reconsider the validity of its ideology, or even demonstrate the faults in the group's actions. They can play a significant role in pushing an individual to abandon terrorist beliefs, attitudes, or behaviour, or prevent a curious individual from engaging in the first place. The transformative power of counternarratives, however, is contingent not only on what the counternarrative says, but how the counternarrative's source is perceived by target audiences. The failure of the ill-fated 'Think Again, Turn Away’ programme is illustrative of this fact. Although the messages that were distributed as part of the programme may have been accurate, the sources attached to those messages were not trusted by their intended targets. As a result, the messages were rejected, and any persuasive effectiveness they might have had was rendered moot.

The purpose of this paper has been to develop a set of preliminary guidelines for overcoming barriers to persuasion experienced by programs like 'Think Again, Turn Away' by making counternarratives more credible and increasing audience trust in a counternarrative's sourcea necessary precondition of counternarrative effectiveness. ${ }^{69}$ The emerging literature on the role of trust within the psychology of terrorist decision-making demonstrates that trust in a message's source has the potential to outweigh any action or ideology. In short, trust and distrust play significant roles in the decision-making processes leading a person to initially join (or ultimately leave) a terrorist group. ${ }^{70}$ Therefore, both the content and the sources of 
counternarratives designed to deter support for terrorism must be perceived as credible if the messages are to be effective. The guidelines presented here can help researchers, practitioners, and policymakers achieve this critical goal with counternarratives intended to reduce support for terrorism.

\section{Acknowledgments}

The authors would like to thank the anonymous reviewers for their comments and suggestions. We would also like to thank the editorial team of this special issue, especially Josefin Graef, for their patience, guidance and support.

\section{Notes on Contributors}

Dr. Kurt Braddock is an Assistant Teaching Professor of Communication Arts and Sciences and Homeland Security at The Pennsylvania State University.

Dr. John F. Morrison is the Director of the Terrorism and Extremism Research Centre at the University of East London.

\section{Notes}

\footnotetext{
${ }^{1}$ Rita Katz, “The State Department's Twitter War with ISIS is Embarrassing," Time (2014, September 16). Available at http://time.com/3387065/isis-twitter-war-state-department/ (Accessed August 12 ${ }^{\text {th }}, 2017$ ) Greg Miller and Scott Higham, "In a Propaganda War against ISIS, the U.S. Tried to Play by the Enemy's Rules," The Washington Post (2015, May 8). Available at https://www.washingtonpost.com/world/national-security/ina-propaganda-war-us-tried-to-play-by-the-enemys-rules/2015/05/08/6eb6b732-e52f-11e4-81ea0649268f729e_story.html (Accessed, August 12 ${ }^{\text {th }}, 2017$ )

${ }^{2}$ Katz, "The State Department's Twitter War."

${ }^{3}$ Miller and Higham, "In a Propaganda War against ISIS."

${ }^{4}$ Kurt Braddock and John Horgan, "Towards a Guide for Constructing and Disseminating Counternarratives to Reduce Support for Terrorism," Studies in Conflict and Terrorism 39(5) (2016), pp. 381-404.

${ }^{5}$ Braddock and Horgan, "Towards a Guide for Constructing and Disseminating Counternarratives to Reduce Support for Terrorism," pp. 392-394.

${ }^{6}$ John Horgan, The Psychology of Terrorism, $2^{\text {nd }}$ Edition (London: Routledge, 2014).

${ }^{7}$ S. Shyam Sundar, "The MAIN Model: A Heuristic Approach to Understanding Technology Effects on Credibility," in Miriam J. Metzger and Andrew J. Flanagin, eds., Digital Media, Youth, and Credibility (Cambridge, MA: MIT Press), pp. 73-100.

${ }^{8}$ Diego Gambetta, “Can We Trust Trust?" in Diego Gambetta, ed., Trust: Making and Breaking Cooperative Relations (Oxford, UK: Basil Blackwell, 2000), pp. 213-238.

${ }^{9}$ Adam B. Seligman, The Problem of Trust (Princeton, NJ: Princeton University Press, 1997).

${ }^{10}$ Brian C. Rathbun, "It Takes All Types: Social Psychology, Trust, and the International Relations Paradigm in Our Mind," International Theory 1(3) (2009), pp. 345-380.

${ }^{11}$ Ibid.

${ }^{12}$ Horgan, The Psychology of Terrorism.

${ }^{13}$ John F. Morrison, "The Trustworthy Terrorism: The Role of Trust in the Psychology of Terrorism," in Orla Lynch and Javier Argomaniz, eds., Victims and Perpetrators- Understanding the Complexity of Terrorism (London: Routledge, 2017).

${ }^{14}$ John Horgan, Walking Away from Terrorism: Accounts of Disengagement from Radical and Extremist Movements (London: Routledge, 2009), p. 152.

${ }^{15}$ Alex P. Schmid, Radicalisation, De-Radicalisation, Counter-Radicalisation: A Conceptual Discussion and Literature Review (The Hague, Netherlands: International Centre for Counter-Terrorism, 2013).
} 
${ }^{16}$ Morrison, "The Trustworthy Terrorism."

${ }^{17}$ Karen M. Fierke, "Terrorism and Trust in Northern Ireland," Critical Studies on Terrorism 2(3) (2009), pp. 497-511.

${ }^{18}$ Thomas Hegghammer, “The Recruiter's Dilemma: Signalling and Rebel Recruitment Tactics," Journal of Peace Research 50(1) (2013), pp. 3-16.

${ }^{19}$ Morrison, "Trust in Me," pp. 47-56.

${ }^{20}$ Horgan, The Psychology of Terrorism, pp. 140-141.

${ }^{21}$ Ibid.

${ }^{22}$ Paul Gill, Noemie Bouhana, and John F. Morrison, "Individual Disengagement from Terrorist Groups," in Caroline Kennedy-Pipe, Gordon Clubb, and Simon Mabon, eds., Terrorism and Political Violence (London: Sage, 2015), pp. 243-257.

${ }^{23}$ Morrison, "The Trustworthy Terrorism."

${ }^{24}$ Horgan, Walking Away from Terrorism, pp. 20-39.

${ }^{25}$ Omar Nasiri, "Focus: My Life as a Spy at the Heart of Al Qaeda," The Sunday Times, (2006, November 19), pp. 14-15.

${ }^{26}$ Horgan, Walking Away from Terrorism, p. 33.

${ }^{27}$ Michael Jacobsen, Terrorist Dropouts: Learning from Those Who Have Left (Policy Focus Paper \#101)

(Washington, DC: Washington Institute for Near East Policy, 2010).

${ }^{28}$ Horgan, The Psychology of Terrorism.

${ }^{29}$ Braddock and Horgan, "Towards a Guide for Constructing and Disseminating Counternarratives to Reduce Support for Terrorism," pp. 392-393.

${ }^{30}$ See Gabriel Weimann, Terror on the Internet (Washington, DC: United States Institute of Peace Press, 2006).

${ }^{31}$ Brendan I. Koerner, "Why ISIS is Winning the Social Media War," Wired, April 2016. Available at https://www.wired.com/2016/03/isis-winning-social-media-war-heres-beat/ (accessed 10 April 2017).

${ }^{32}$ Sundar, "The MAIN Model," pp. 73-100.

${ }^{33}$ B. J. Fogg, Cathy Soohoo, David R. Danielson, Leslie Marable, Julianne Stanford, and Ellen R. Tauber,

"How Do Users Evaluate the Credibility of Web Sites? A Study with Over 2,500 Participants." Paper presented at the ACM Conference on Designing for User Experiences. (2003). Available at

https://pdfs.semanticscholar.org/4c8f/e677cddc84a058491f51701c2edbbaa5aefa.pdf (accessed April 2, 2017).

${ }^{34}$ Sundar, "The MAIN Model," pp. 73-100.

${ }^{35}$ Ibid, p. 78.

${ }^{36}$ Sundar, "The MAIN Model," pp. 73-100.

${ }^{37}$ Andrew J. Flanagin and Miriam J. Metzger, "Digital Media and Youth: Unparalleled Opportunity and Unprecedented Responsibility," in Miriam J. Metzger and Andrew J. Flanagin, eds., Digital Media, Youth, and Credibility (Cambridge, MA: MIT Press, 2008), pp. 5-28.

${ }^{38}$ Sundar, "The MAIN Model," p. 83.

${ }^{39}$ See, for example, Jerome Durlak, "A Typology for Interactive Media," in Margaret J. McLaughlin, ed., Communication Yearbook No. 10 (Newbury Park, CA: Sage, 1987), pp. 743-757; Carrie Heeter, "Implications of New Interactive Technologies for Conceptualizing Communication," in Jerry Salvaggio and Jennings Bryant, eds., Media in the Information Age: Emerging Patterns of Adoption and Consumer Use (Hillsdale, NJ: Lawrence Erlbaum, 1989), pp. 217-235.

${ }^{40}$ S. Shyam Sundar, Sriram Kalyanaraman, and Justin Brown, "Explicating Web Site Interactivity: Impression Formation Effects in Political Campaign Sites," Communication Research 30(1) (2003), pp. 30-59.

${ }^{41}$ Braddock and Horgan, "Towards a Guide for Constructing and Disseminating Counternarratives to Reduce Support for Terrorism," pp. 381-404.

${ }^{42}$ See Braddock and Horgan (2016) for a discussion of details concerning the contexts in which counternarratives are distributed.

${ }^{43}$ See Horgan, Walking Away from Terrorism, pp. 20-39; Tore Bjørgo and John Horgan, eds., Leaving Terrorism Behind: Individual and Collective Disengagement (Oxon, UK: Routledge, 2009), pp. 36-42 for descriptions of terrorist disillusionment with their experiences in terrorist groups.

${ }^{44}$ Horgan, Walking Away from Terrorism.

${ }^{45}$ Green and Brock, "In the Mind's Eye,” pp. 315-341; Moyer-Gusé, “Toward a Theory of Entertainment Persuasion," pp. 407-425.

${ }^{46}$ Braddock and Horgan, "Towards a Guide for Constructing and Disseminating Counternarratives to Reduce Support for Terrorism," pp. 381-404.

${ }^{47}$ See Alberto Ardévol-Abreu, Catherine M. Hooker, and Homero Gil de Zúñiga, "Online News Creation, Trust in the Media, and Political Participation: Direct and Moderating Effects Over Time," Journalism 18, in press; Anthony J. Gaughan, "Illiberal Democracy: The Toxic Mix of Fake News, Hyperpolarization, and Partisan Election Administration,” Duke Journal of Constitutional Law \& Public Policy 12(3), pp. 57-139. 
${ }^{48}$ Alexandra List, Patricia A. Alexander, and Lori A. Stephens, "Trust but Verify: Examining the Association between Students' Sourcing Behaviors and Ratings of Text Trustworthiness," Discourse Processes 54(2) (2017), pp. 83-104.

${ }^{49}$ Rick Busselle and Helena Bilandzic, "Fictionality and Perceived Realism in Experiencing Stories: A Model of Narrative Comprehension and Engagement," Communication Theory 18 (2006), pp. 255-280; Emily Moyer Gusé, "Toward a Theory of Entertainment Persuasion: Explaining the Persuasive Effects of EntertainmentEducation Messages," Communication Theory 18 (2008), pp. 407-425.

${ }^{50}$ Braddock, "The Utility of Former Offenders"; Braddock and Horgan, "Towards a Guide for Constructing and Disseminating Counternarratives to Reduce Support for Terrorism," pp. 381-404.

${ }^{51}$ See Braddock and Horgan, "Towards a Guide for Constructing and Disseminating Counternarratives to Reduce Support for Terrorism,” pp. 381-404; Jeffry R. Halverson, H. L. Goodall Jr., and Steven R. Corman, Master Narratives of Islamic Extremism (New York: Palgrave Macmillan, 2011).

${ }^{52}$ Jack W. Brehm, A Theory of Psychological Reactance (New York: Academic Press, 1966).

${ }^{53}$ Zachary Abuza, "Education and Radicalization: Jemaah Islamiyah Recruitment in Southeast Asia," in James

J. F. Forest, ed., The Making of a Terrorist: Recruitment, Training, and Root Causes, Vol. 1 (Westport, CT: Praeger, 2006), pp. 66-84; Morrison, “Trust in Me," pp. 47-56.

${ }^{54}$ Braddock and Horgan, "Towards a Guide for Constructing and Disseminating Counternarratives to Reduce Support for Terrorism," pp. 381-404.

${ }^{55}$ Braddock, "The Utility of Former Offenders."

${ }^{56}$ Steven R. Corman and Jill S. Schiefelbein, "Communication and Media Strategy in the Islamist War of Ideas," in Steven R. Corman, Angela Tretheway, and H. Lloyd Goodall, eds., Weapons of Mass Persuasion (New York: Peter Lang Publishing, 2008), p. 93.

${ }^{57}$ Braddock and Horgan, "Towards a Guide for Constructing and Disseminating Counternarratives to Reduce Support for Terrorism," pp. 381-404.

${ }^{58}$ Silvia Knobloch-Westerwick, "Mood Management: Theory, Evidence, and Advancements," in Jennings Bryant and Peter Vorderer, eds., Psychology of Entertainment (Mahwah, NJ: Lawrence Erlbaum, 2006), pp. 239-254.

${ }^{59}$ Braddock and Horgan, "Towards a Guide for Constructing and Disseminating Counternarratives to Reduce Support for Terrorism," pp. 381-404; Melanie C. Green and Timothy C. Brock, "In the Mind's Eye:

Transportation-Imagery Model of Narrative Persuasion," in Melanie C. Green, Jeffrey J. Strange, and Timothy C. Brock, eds., Narrative Impact: Social and Cognitive Foundations (Mahwah, NJ: Lawrence Erlbaum, 2002), pp. 315-341; Moyer-Gusé, “Toward a Theory of Entertainment Persuasion,” pp. 407-425.

${ }^{60}$ Todorov, Chaiken, and Henderson, "AIMQ: A methodology for information quality assessment," pp. 195212.

${ }^{61}$ Richard Y. Wang and Diane M. Strong, "Beyond Accuracy: What Data Quality Means to Data Consumers," Journal of Management Information Systems 12(4) (1996), pp. 5-33.

${ }^{62}$ Anthony J. Hornof, "Cognitive Strategies for the Visual Search of Hierarchical Computer Displays," HumanComputer Interaction 19(3) (2004), pp. 183-223.

${ }^{63}$ Hierarchical organization is distinct from interactive organization (as outlined in the discussion of the Choice Heuristic, resulting in Interactivity Recommendations 3a and 3b). Whereas hierarchical organization relates to the emphasis of certain content to promote user selection of that content, interactive organization relates to the simplicity with which the user can make choices about which content to engage with.

${ }^{64}$ John Morrison and Kurt Braddock, "Agency Cues and Trust in Strategic Counter-messaging Intended to

Reduce Support for Terrorism," in progress.

${ }^{65}$ Sundar, "The MAIN Model," pp. 73-100.

${ }^{66}$ Mia Bloom, Hicham Tiflati, and John Horgan, "Navigating ISIS's Preferred Platform: Telegram," Terrorism and Political Violence, in press.

${ }^{67}$ Braddock and Horgan, "Towards a Guide for Constructing and Disseminating Counternarratives to Reduce Support for Terrorism," pp. 381-404.

${ }^{68}$ Kurt Braddock, "Ghosts in the Machine: The Efficacy of Simulated-Reality Messaging Intended to Reduce

Support for Terrorism," in progress.

${ }^{69}$ Ibid.

${ }^{70}$ Morrison, "The Trustworthy Terrorism." 